\title{
ポリアニリンの電気特性に及ぼす有機酸ドーパントの影響
}

\author{
島田恵理子*，槄＼cjkstart孝二
}

\section{The Effects of Organic Acid Dopants on the Electric Properties of Polyanilines}

\author{
Eriko SHIMADA* and Koji TACHIBANA
}

Received November 10, 1995 ; Accepted December 18, 1995

\begin{abstract}
The electric properties of compressed specimen of polyanilines (PAns), which had been doped with organic acids (chloroacetic acid or dichloroacetic acid), were investigated by comparing with the specimen doped with an inorganic acid (hydrochloric acid). At room temperature, a stronger acid dopant tends to give higher dc-conductivity than weaker acid ones. From the analysis of the temperature dependence of dc-conductivity by the 3 dimensional VRH model, the hopping conduction mode was found to be independent of the kinds of dopant acids. The inductance component of an equivalent circuit for ac-impedance spectra of the specimens was found to be markedly influenced by dopant acid property. This component is explained to give rise to due to the disturbance of local electric field, when the dopants in PAns are rearranged alternatively with the vibrational external electric field.
\end{abstract}

\section{1 緒 言}

ポリアニリン (PAn) はプロトン酸をドープするこ とで導電性を発現する高分子として知られている，その 導電機構は, PAn 骨格の酸化還元と窒素原子へのプロ トンの付加を含むため, 他の非縮退系導電性高分子に比

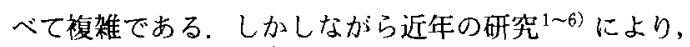
プロトン化による導電機構については, バイポーラロン からポーラロンができ，さらにポーラロニック金属塊が 形成するという解秎が最も有力となっている.

このようにして, 主に塩酸または硫酸を使用した場合 のプロトン化によるPAnの導電機構はかなり明らかに なってきた。

PAnのドーピングの際には, プロトンのみならず酸 分子全体が取り込まれているので, 異なる酸を用いれば 物性にも違いが生ずることが予想される。しかしながら， 酸強度の強い（pKa が小さい）ドーパントを用いた方 が、同じドーパント濃度における直流導電率が大きいと いうことが経験的に知られているすほかは，酸の種類に よる電気的特性への影響についてはほとんど明らかにさ れていない。

本報ではドーパント酸の種類に注目して, 有機酸をドー 東京理科大学理学部化学科（干162 東京都新宿区神楽坂 1-3） Department of Chemistry, Faculty of Science, Science University of Tokyo (Kagurazaka 1-3, Shinjuku-ku, Tokyo 162, Japan)

Key Words : Polyaniline, Organic Acid Dopant, Ac-impedance, Inductance
プしたPAnの直流導電率の温度変化, 光学吸収および 交流インピーダンススベクトルを，塩酸をドープした場 合のものと比較することにより，その電気的特性につい て検討した。

\section{2 実験方法}

\section{1 試料片の作製}

試料片はこれまでと同様，以下のように作製した ${ }^{8 \sim 10}$. $1.0 \mathrm{~mol} / \mathrm{dm}^{3}$ アニリンと $2.0 \mathrm{~mol} / \mathrm{dm}^{3}$ 塩酸の混合水溶 液中で電解酸化重合して得たPAn 粉末を約 $0.1 \mathrm{~mol} /$ $\mathrm{dm}^{3}$ アンモニア水溶液で脱塩酸処理をし, 乾燥させて 未ドープ PAnとした この末ドープPAn 粉末を $0.01 \sim 0.10 \mathrm{~mol} / \mathrm{dm}^{3}$ の各種濃度に調製したプロトン酸 水溶液にドーピングが平衡に達するまで浸して,ドーパ ント濃度を調節した。ドーピングが完了したPAn 粉末 は滤別して乾燥させた後, 電気的测定用には压樎ペレ ットに，光学吸收測定用には $\mathrm{KBr}$ 錠剤にした。また， $\mathrm{X}$ 線回折には粉末をそのまま用いた。 ドーパント酸 には弱酸で多原子分子の有機酸であるク口ロ酢酸 $\mathrm{CH}_{2} \mathrm{ClCOOH}$ とジクロロ酢酸 $\mathrm{CHCl}_{2} \mathrm{COOH}$ を用い (Table 1)，比較のために塩酸 $\mathrm{HCl}$ を使用した。

\section{2 測 定}

直流導電率はこれまでと同じく四端子法を採用し ${ }^{8 \sim 10)}$, 湿度の影響を除くため作製した気密性の試料室（銅製） の中にて, 温度範囲 77 300 K で測定した。交流イン ピーダンス測定も以前 $\mathrm{HCl}$ をドープしたPAnに行なっ 
Table 1 Dissociation constants, $\mathrm{pKa}$, of protonic acids in aqueous solution ${ }^{13)}$.

(at $25^{\circ} \mathrm{C}$ )

\begin{tabular}{cc}
\hline Protonic acid & $\mathrm{pKa}$ \\
\hline $\mathrm{HCl}$ & -7 \\
$\mathrm{CHCl}_{2} \mathrm{COOH}$ & 1.48 \\
$\mathrm{CH}_{2} \mathrm{ClCOOH}$ & 2.85 \\
\hline
\end{tabular}

たときのもの ${ }^{9)}$ と同様に, 圧縮ペレットの両面に導電ペー ストで白金線の端子を取り付け，乾嬠空気中室温で行なっ た、酸をドープした試料片の導電率はいずれも $10^{-6} \mathrm{~S} /$ $\mathrm{cm}$ 以上であったので，ガードリング電極を取り付けず に测定した ${ }^{9,12)}$ 。交流周波数は 0.1 から $1.0 \times 10^{5} \mathrm{~Hz}$,

振幅は $5.0 \mathrm{mV}$ とした。インピーダンス測定には Model 378 electro-chemical impedance system (EG \& G Princeton Applied Research)を用いた. 光学吸収は 250 2000 $\mathrm{nm}$ の波長範囲で測定した。

\section{3 結果および考察}

\section{1 直流導電率および光学吸収スペクトル}

室温での直流導電率 $\sigma$ を Fig. 1 に示す. pKa が小さ い酸はど（Table 1）すなわち強い酸ほど, 同じドーパ ント濃度 $(x \mathrm{~mol} \%)$ に扔ける導電率は高い之いう傾 向が見られた。これまでに我々が得ている熱電能あるい はホール効果の結果 ${ }^{10)}$ から, ドーパント濃度が $30 \mathrm{~mol}$ \%以下では，どのような酸を用いた場合でもキャりアー はホールであることがわかって扔り，また光学吸収のピー ク位置に変化がない(10) (Fig. 2)ことからむ，異なる酸 をドープしても電子のエネルギー状態に大差は生じない, と判断した。また，X線回折では大部分がアモルファ スであることがわかった（結晶化度〜15\%）が，結晶部 分の回折パターンは Pouget らの報告 ${ }^{6)}$ にあったものと 酷似しており，斜方晶のような周期性を表していた，回 折ピーク位置や強度比が酸の種類あるいは濃度によって 变わらないことから，大きい酸による格子の膨張は抗こ らず，酸の入っている場所は同じであると考えて良いこ とが分かった。

一定の温度で测定したマクロな四端子法直流導電率の 測定では，粒界での伝導やホッピング伝尊の区別は出来 ない，ホッピング伝導を観測する手段の一つには， $\sigma$ の 温度低存性を調べるということ代挙げられる.

Mottの 3 次元の VRH モデル ${ }^{11)}$ によると， $\sigma$ 上温 度 $T$ の間には(1) 式のような関係がある ${ }^{5,11)}$.

$$
\sigma=2\left[9 \alpha N_{0} /\left(8 \pi k_{\mathrm{B}} T\right)\right)^{1 / 2} \nu_{0} \exp \left[-\left(T_{0} / T\right)^{1 / 4}\right]
$$

ここで， $\alpha$ は局在波動関数の減定距離， $k_{\mathrm{B}}$ はボルッマ ン定数, レ。はフォノンの振動数，また $N_{0}$ はフェルミ 準位に扔ける状態密度を表す。 $T_{0}$ は局在波動関数の減 衰距離の関数であり，(2)式で与えられる.
$T_{0}=16 /\left(k_{\mathrm{B}} N_{0} \alpha^{3}\right)$

(1) 式に基づいて， $\sigma$ 上温度の関係をプロットすると， Fig. 3 および 4 のようにいずれも良い直線が得られ， 本研究に用いた試料に対してこのモデルが適用できるこ とが示された。これらの直線の傾き $T_{0}$ をドーパント濃 度に対してプロットし, 酸の種類および濃度による局在 状態の違いを調べた（Fig. 5)，比較のために同様にし て求めた塩酸ドープのPAnのデータも載せた.

これらをみると，酸の違いによってホッピング伝導部 分への影響は現れないことが分かる。つまり，直流導電 率に対する酸の違いによる影響は，ホッピング伝導以外， すなわちキャリアーが分子銷上を移動するときに表れる と考えられる.

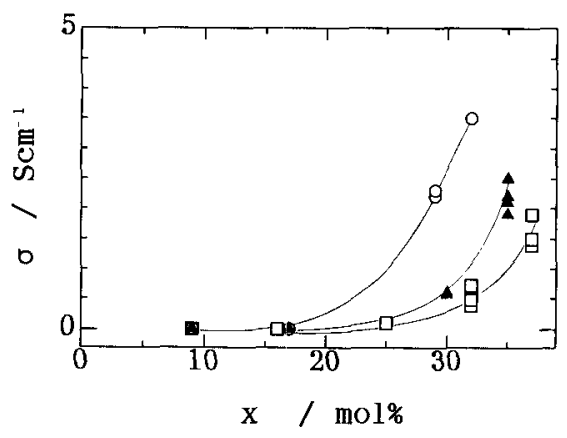

Fig. 1 Dc-conductivity $(\sigma)$ at room temperature vs. dopant concentration $(x)$ for PAns doped with protonic acids $\left(\mathrm{O}: \mathrm{HCl}, \square: \mathrm{CH}_{2} \mathrm{ClCOOH}\right.$,

$\Delta$ : $\mathrm{CHCl}_{2} \mathrm{COOH}$ ).

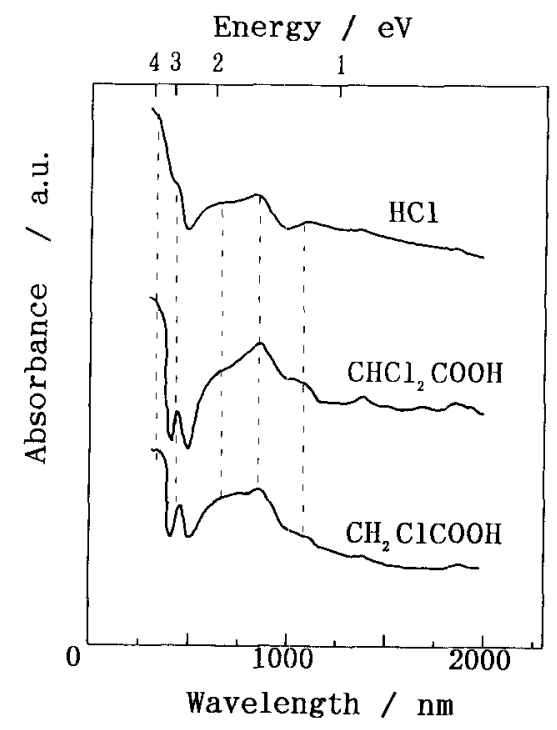

Fig. 2 Optical absorption spectra of PAns doped with protonic acids in concentration of ca. 17 mol \%. 


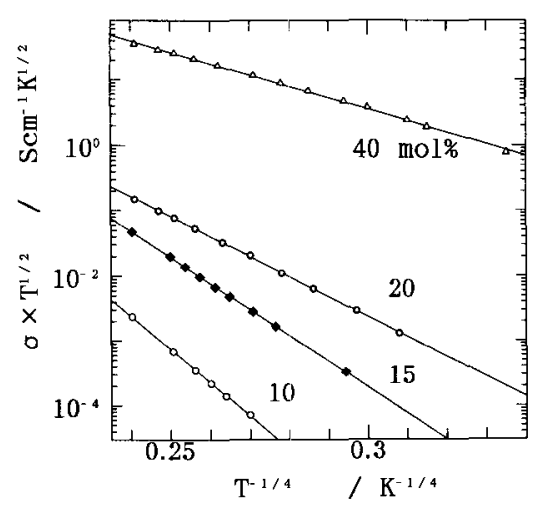

Fig. $3 \log \left(\sigma \times T^{1 / 2}\right)$ vs. $T^{-1 / 4}$ for $\mathrm{CH}_{2} \mathrm{ClCOOH}-$ doped PAns.

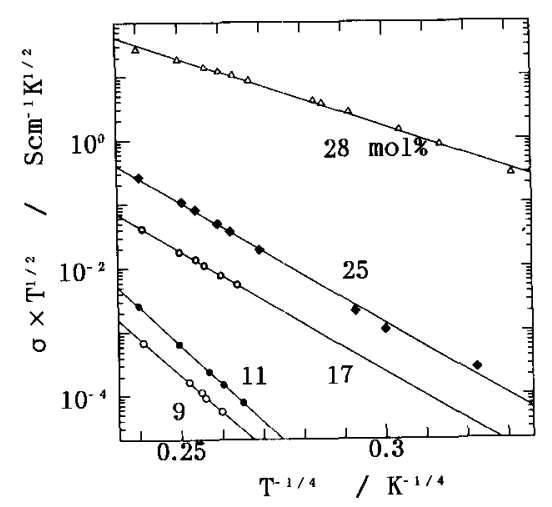

Fig. $4 \log \left(\sigma \times T^{1 / 2}\right)$ vs. $T^{-1 / 4}$ for $\mathrm{CHCl}_{2} \mathrm{COOH}$ doped PAns.

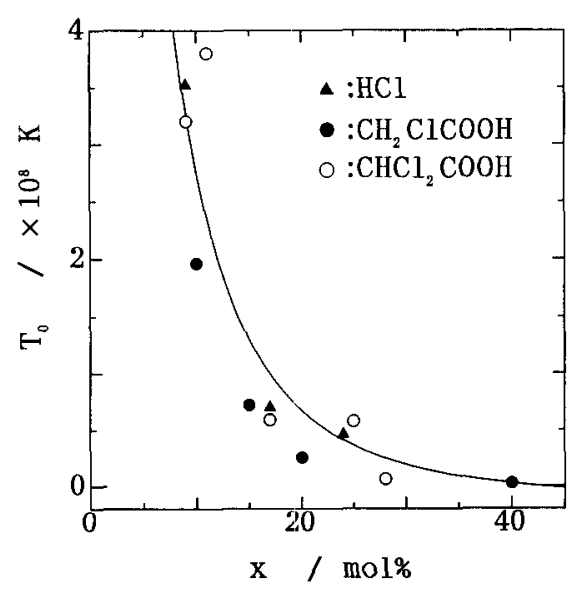

Fig. $5 T_{0}$ vs. dopant concentration $(x)$ for PAn doped with protonic acids, $\mathrm{CH}_{2} \mathrm{ClCOOH}, \mathrm{CHCl}_{2}$ $\mathrm{COOH}$, and $\mathrm{HCl}$.

\section{2 交流インピーダンス}

クロロ酢酸, およびジクロロ酢酸をドープしたPAn 試料片の交流インピーダンススペクトルの一例を Fig. 6 および 7 に示す ( $\times$ 盯が実験值). Fig. 8 は塩酸ドー プのむのである．濃度功增すにつれゆがんだ半円状のス ペクトルが小さくなりつつシフトし，インピーダンスベ クトルは小さくなる。この傾向は，ドーパント濃度が比 較的小さいときは有機酸を用いても同樣に見られた．有 機酸を用いた場合に塩酸の場合と異なるのは，高周波側 の虚軸の值が負になり，さらに高周波侧で弧を描く特徽 的な軌跡を示すようになる点である（Fig.6，7）。考え られる電気的回路で, インピーダンススペクトルの虚軸 を負の值にまで小さくするようなものは, インダクタン ス成分だけである。

我々は以前に塩酸ドープのPAnのインピーダンスを 测定し, 且つそのシミェレーションを行なった ${ }^{9)}$ 。その 際に, 試料と電極との界面およひ試料中の粒界のインピー ダンスを試料片の SEM 表面・断面写真をもとに分離し, 試料に固有な（inherent）インピーダンスをドーパン

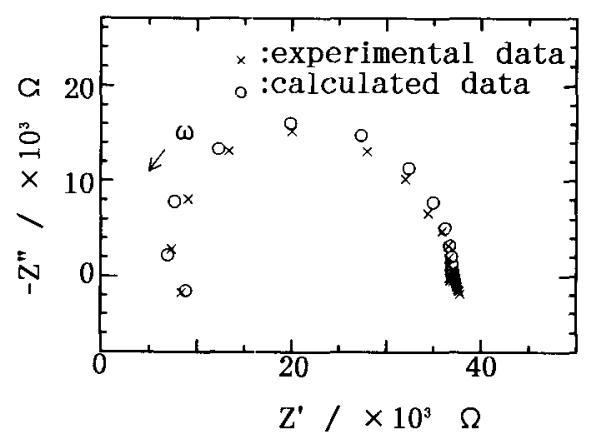

Fig. 6 Complex imoedance plane plots of PAn doped with $\mathrm{CH}_{2} \mathrm{ClCOOH}$ and simulated result $(x=17 \operatorname{mol} \%)$.

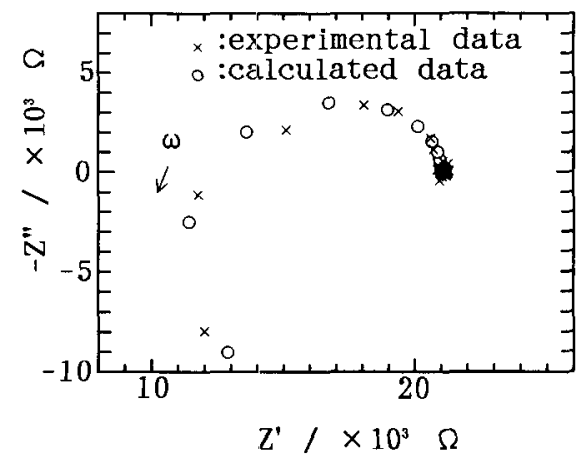

Fig. 7 Complex impedance plane plots of PAn doped with $\mathrm{CHCl}_{2} \mathrm{COOH}$ and simulated result $(x=16 \mathrm{~mol} \%)$. 


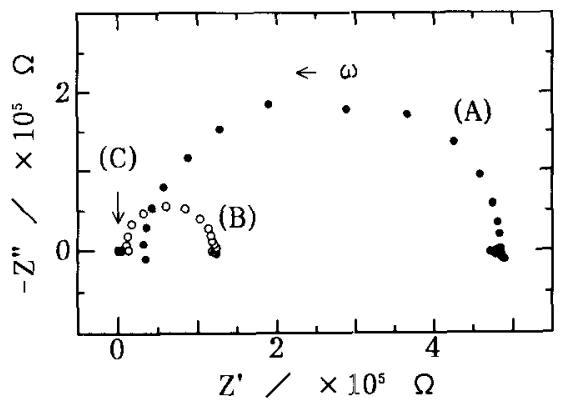

Fig. 8 Complex impedance plane plots of PAn doped with HCl. Value of $x$; (A) 9.2, (B) 17.0 , (C) $29.0 \mathrm{~mol} \%$ or above.

ト濃度と関連させた等価回路モデルを提案した ${ }^{9}$ (Fig. 9 および Fig. $10 \mathrm{~A}$ )。これは, 未ドープの状態でのキャ リアーの導電パスに，ドープに伴って発生した新しいパ スが增殖してゆくという概念に基づき構成されている.

Fig. 10 A はFig. 9 簡単にしたものであり，Rはキャ リアーが分子鎖上（または金属領域）を移動していると き, $\mathrm{C}_{0}, \mathrm{r}_{\mathrm{o}}$ または $\mathrm{C}_{\mathrm{n}}, \mathrm{r}_{\mathrm{n}}$ の並列回路部分は分子鎖間 （または局在準位間）を移動するときのインピーダンス にそれぞれ対応している。ここで添字。， nはそれぞれ original, new 意味する.

この回路モデルの拡張として, 有機酸をドープした試 料について、インダクタンスを組み込んだ等価回路を検 討した (Fig.10 B，C). キャリアーがどこでインダク タンスの影響を受けるかで大別をると，分子鎖上（また は金属領域）を移動するとき（Fig. $10 \mathrm{~B} ）$ と分子鎖間 （または局在準位間）を移動するとき（Fig.10 C）とな る.

本測定に用いた最も高い周波数の $1.0 \times 10^{5} \mathrm{~Hz}$ が，試 料に対して充分高周波数であるよいう仮定のもとで，こ れらの回路のインピーダンスを計算してみると, 前述の ようなスペクトルの高周波側でつ特徴を示すすのは, Fig.10の中でB-a しかないこ之が分かった．塩酸ドー プの場合と同様な力法9゙でシミュレーションした結果 の一部を, 前出の Fig. 6 および 7 に○印で示した.

この回路の物理的な意味は, 岡值なPAn 鎖の間に入っ ているドーパント酸の双極子モーメントが，振動電場に 応答して再配列する際に，局所的な電場の向きが変わる ことに符合していると考えた。郡所的な電場の乱れは, ドーパントの動き易さと双極子キーメントの大きさで見 積もることができるとし，ドーパントの分子量 $(M)$ に 分子の長さ $(L)$ を乗じたものをその動き易さの目安に, またこれに永久双極子モーメントの大きさ $(\mu)$ を乗じた ものを局所的な電場の乱饥易さの目安 (ILED ; index of localized electric disturbance と呼ぶことにする) として概算し, Table 2 に示した. Fig. 11 は，それぞ

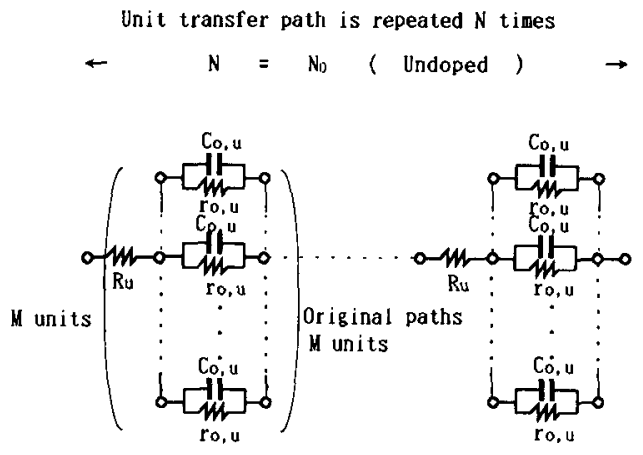

$\Downarrow$ Doping

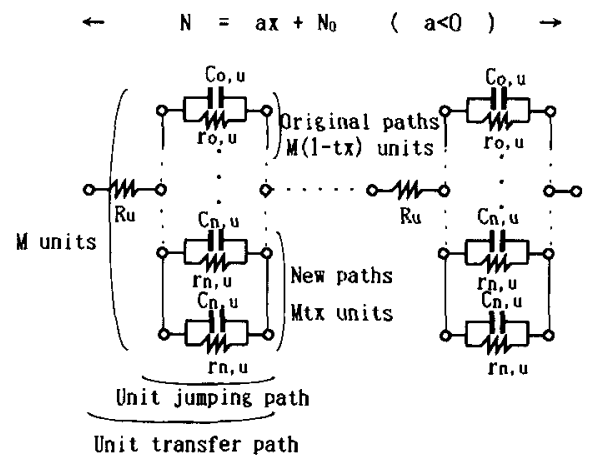

Fig. 9 A circuit model of conductivity propagation mode of PAn with doping $\mathrm{HCl}$. Upper : total equivalent circuit of the inherent part. Lower : propagation model of new paths related to dopant concentration $x$. Subscripts $o, n$, and $u$ mean original, new, and unit, respectively.

れの試料片 $(x \approx 17 \mathrm{~mol} \%)$ のインピーダンスのシミュ レーションに用いたインダクタンスの值を，ILEDに対 してとったものである.インダクタンスとILEDとの 間に良い相関が見られるこ之から，本実験に用いたドー パントについては，インダクタンスがPAn中のドーパ ントの電気的な動きを表していると解釈出来る.

この等価回路でインピーダンススペクトルをシミュレー ションすると, ドーパントの濃度が高くなるにつれてイ ンダクタンスの值が小さくなっていくが，これはドーパ ント酸の濃度が高くなると, 双極子間の相互作用が增加 して動きづらくなるためであろう.

ドーパントの大きさと双極子モーメントの組み合わせ によっては，インダクタンス成分のさらに大きいPAn 試料片を作製することも可能であると思われる。 
( A )

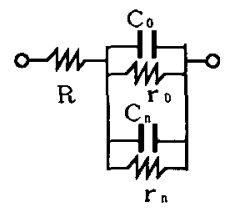

( B )

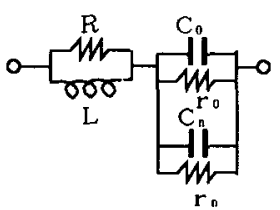

$\mathrm{B}-\mathrm{a}$

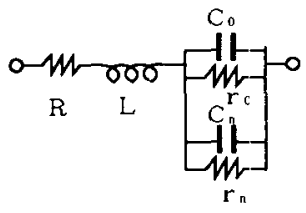

$B-b$

( C )

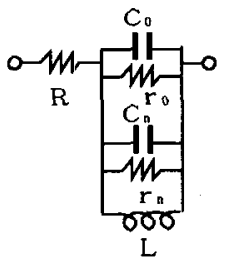

$\mathrm{c}-\mathbf{a}$

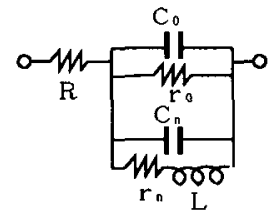

$c-b$

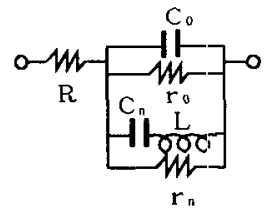

$\mathrm{C}-\mathrm{c}$

Fig. 10 Equivalent circuit models of inherent part not containing inductance component (A), and containing inductance component (B, C). Difference in physical meaning between (B) and (C) is given in the text.

Table 2 Physicochemical properties of dopant acids.

\begin{tabular}{|c|c|c|c|c|}
\hline $\begin{array}{c}\text { Protonic } \\
\text { acid }\end{array}$ & $\begin{array}{l}\text { Molecular } \\
\text { weight }(M)\end{array}$ & $\begin{array}{l}\text { Molecular } \\
\text { length }(L)^{*}\end{array}$ & $\begin{array}{c}\text { Dipole } \\
\operatorname{moment}(\mu)^{* *}\end{array}$ & $\begin{array}{l}\text { ILDE } \\
(M L \mu)\end{array}$ \\
\hline $\mathrm{HCl}$ & 36.5 & $1.3 \AA$ & $1.1 \mathrm{D}$ & 52 \\
\hline $\mathrm{CH}_{2} \mathrm{ClCOOH}$ & 94.5 & 4.5 & 2.1 & 893 \\
\hline $\mathrm{CHCl}_{2} \mathrm{COOH}$ & 128.9 & 4.5 & 1.8 & 1044 \\
\hline
\end{tabular}

* Calculated on a molecular model.

* * Calculated from values of group moment ${ }^{14)}$

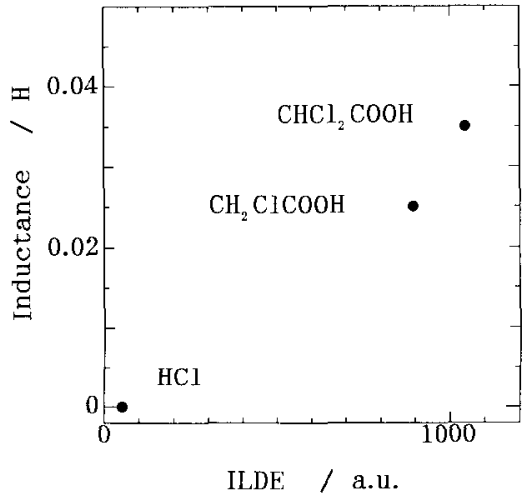

Fig. 11 Plot of inductance value and index of localized electric disturbance (ILED). $x \approx 17 \mathrm{~mol} \%$

\section{4 結 論}

PAnにドープするプロトン酸として，有機酸（クロ 口酢酸, ジクロロ酢酸; を用いることによって現れる電 気的特性について，塩酸ドープの場合のものと比較・検 討した，㨁流導電率に対しては，酸強度が強いはよ゙すな わち $\mathrm{pKa}$ が小さいほど大きい導電率が得られる傾向が あるが，この違いにはホッピング伝導部分は関与してい ないことが，VRHモ汸ルを使って明らかにされた。交 流インピーダンス测定により，特に有機酸をドープした 場合にはインダクタンス成分が加わることが分かった。 その等価回路の物理的な意昧は, 剛直なポリマー鎖の間 に入った有機酸が振動電場に心答して再配列しようとす る際に，局所的な電場ゆ乱れが起こることに对応してい る.

最後に，低温測定にあたって貴重な提言と援助をいた だいた東京理科大学理学部物理学科講師 小池茂年氏に 感謝致します.

\section{攻献}

1) F. Zuo, M. Angelo ooulos, A.G. MacDiarmid and A.J. Epstein, Phys. Rer. B, 36, 3475 (1987). 
2) A.J. Epstein, J.M. Ginder, F. Zuo, R.W. Bigelow, H.S. Woo, D.B. Tanner, A.F. Richter, W.S. Huang and A.G. MacDiarmid, Synth. Met, 18, 303 (1987).

3) J.M. Ginder, A.F. Richter, A.G. MacDiarmid and A.J. Epstein, Solid State Commun., 63, 97 (1987).

4) S. Stafström, J.L. Brédas, A.J. Epstein, H.S. Woo, D.B. Tanner, W.S. Huang and A.G. MacDiarmid, Phys. Rev. Lett., 59, 1464 (1987).

5) F. Zuo, M. Angelopoulos, A.G. MacDiarmid and A.J. Epstein, Phys. Rev. B, 39, 3570 (1989).

6) J.P. Pouget, M.E. Józefowicz, A.J. Epstein, X. Tang and A.G. MacDiarmid, Macromolecules, 24, 779 (1991).

7）大谷 彰, 近韯化学協会エレクトロニクス部会第 23 回研 究会, 研究会資料, pp.15-22 (1992).

8) E. Shimada and K. Tachibana, Denki Kagaku, 62, 518
(1994).

9) E. Shimada and K. Tachibana, J. Electrochem. Soc., 142, 4078 (1995), in press.

10) E. Shimada and K. Tachibana, submitted to Jpn. J. Appl. Phys.

11) N. Mott, Conduction in Non-Crystalline Materials, Oxford University Press (1987). (訳 : 小島忠宣, 小島 和子, 非晶質材料の電気伝導, 見代工学社, pp.28-30 (1988))

12）中戸義禮, 実験化学講座第 4 版, 第 9 巻 (日本化学会編), 丸善, pp.163-165 (1991).

13) Handbook of Chemistry and Physics (CRC Press, Inc., Florida, 1979) 59 th ed., D-202.

14）化学便覧編集委員会，化学便覧基礎編 II，改訂 2 版，（日 本化学会編)，丸善，pp.1404-1407 (1975). 